Research Article

\title{
Screening of Wilson's Diseases and effect on the Brain at Exon 8
}

\author{
Vanita Pudata $^{{ }^{*}}$, Jhansi Konduru ${ }^{1}$ and Gayatri Madiya ${ }^{2}$ \\ ${ }^{1}$ Department of Biochemistry, Dr. L.Bullayya College, Andhra University, Visakhapatnam, India \\ ${ }^{2}$ Department of Organic Chemistry (Drugs), K.V.B.R.R. College for Women, Osmania University, Hyderabad, India
}

*Corresponding author: Vanita Pudata, Department of Biochemistry, Dr. L.Bullayya college, Andhra University, Visakhapatnam, India, Tel: +91-9985924242;

E-mail: vani.vnt1@gmail.com

Citation: Vanita, P., et al. Screening of Wilson's Diseases and effect on the Brain at Exon 8. (2015) Int J Neurol Brain Disord 2(1): 1-10.

\section{Received Date: November 09, 2014 \\ Accepted Date: January 22, 2014 \\ Published Date: January 28, 2015}

\section{Introduction}

Wilson's disease or hepatolenticular degeneration is an autosomal recessive genetic disorder in which copper accumulates in tissues; this manifests as neurological or psychiatric symptoms and liver disease. Wilson's disease is named after Dr. Samuel Alexander Kinnier Wilson (1878-1937) the British neurologist who first described the condition in 1912 and, since then, studies have revealed many of its associated biochemical disturbances and genetic abnormalities.

It is treated with medication that reduces copper absorption or removes the excess copper from the body, but occasionally a liver transplant is required. The condition is due to mutations in the Wilson disease protein (ATP7B) gene. A single abnormal copy of the gene is present in 1 in 100 people, who do not develop any symptoms (they are carriers). The inheritence pattern of transmission is autosomal recessive (Figure 1). If a child inherits the gene from both parents, he may develop Wilson's disease $\mathrm{e}^{[1-6]}$.

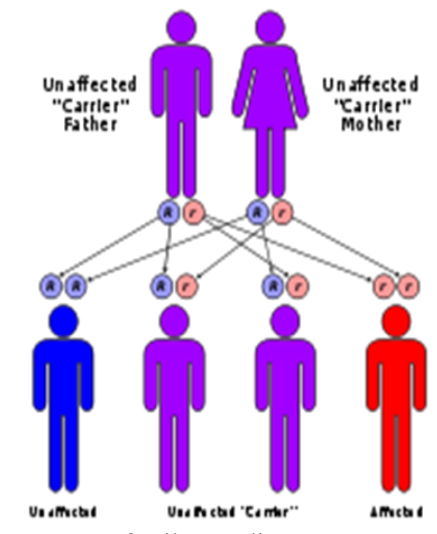

Figure1: Inheritence pattern of Wilson's disease

The known mutations within the ATP7B gene exceed 200 variations, according to the most recent Wilson disease mu-

\section{Abstract}

Wilson disease (WD) is an autosomal recessive disorder caused by defects in ATP7B gene located on chromosome 13q21.1, and manifested as Hepatolenticular degeneration as a result of accumulation of copper. A total number of 20 control samples were taken for studying the mutations in exon 8 . Genomic DNA was prepared from the peripheral blood of the patients. The exon 8 was amplified by PCR using primers. Amplified DNA fragments were analyzed by Agarose gel electrophoresis. Further the patient PCR DNA products will be subjected to Restriction analysis. The results in all controls did not reveal any mutation in the exon 8 of the gene.

tation database. The His1069Gln point mutation in exon 14 of the ATP7B gene is the most frequent mutation in European patients with Wilson's disease. On the other hand, in $20-30 \%$ of Japanese, Korean and Taiwanese patients, another mutation, Arg778Leu in exon 8 is mostly observed. Subjects of the previous studies in china were patients of Han ethnic origin, which compromise $91.9 \%$ of the population of mainland china, according to the fourth census of china carried out in 1990, the remaining $8.1 \%$ of the population is comprised of ethnic minorities, one of which is the Hui ethnic group consisting of about 8.6 million people.

Symptoms usually appear between the ages of 6 and 20 years, but cases in much older patients have been described. The physical burden of the disease falls largely on the liver and brain. A special feature of WD is that medical therapy is used to treat presymptomatic as well as symptomatic individuals, and hepatic transplantation can reverse the metabolic abnormality ${ }^{[7-11]}$.

\section{Epidemiology and Molecular Biology Epidemiology}

WD is present in most populations worldwide, and particularly in those in which consanguineous marriage is common. The disease frequency is estimated to be between 1 in 5,000 and 1 in 30,000, and the carrier frequency is approximately 1 in 90 . A variety of defects have been identified in the ATP7B gene of WD patients, the majority of which are located in the transmembrane region of the associated protein. These defects include insertion, deletion, splice site and point mutations. Many of the mutations identified are described in various databases. In most ethnic groups, either one or a small number of these ATP7B mutations are prevalent, in addition to many other more rare mutations. For instance, among Europeans and North Americans, two ATP7B point mutations-His1069 Gln and Gly1267 Argtogether account for $38 \%$ of the observed mutations in WD. A

Copy rights: (C2014 Vanita P. This is an Open access article distributed under the terms of Creative Commons Attribution 4.0 International License. 
15-nucleotide deletion underlying the most common haplotype seen in Sardinians ${ }^{[12]}$ has been reported and a missense mutation (Arg778 Leu) was found among Mongoloids. Recently in India, seven recurring haplotypes were identified that account for $58 \%$ of the different mutant chromosomes in WD, and four underlying defects in ATP7B representing 37\% of WD chromosomes were also detected. ATP7B is a relatively large gene at around $80 \mathrm{~kb}$, and it contains 21 exons. Knowledge of the prevalent mutations is therefore of help in achieving rapid mutational screening.

\section{Molecular Biology}

WD is caused by mutations to the gene coding for ATPase copper transporting beta polypeptide (ATP7B) ${ }^{[13]}$, which is located on chromosome 13q14.3-21.1 and is expressed predominantly in the liver. The Wilsons disease gene (ATP7B) was identified in 1993. This gene, located on chromosome 13, encodes a putative copper transporting P-type Adenosine triphosphatase and has 21 exons spanning a genomic region of about $80 \mathrm{~kb}$. Length of the gene is 1465 nucleotides.

Normal gene product: The product of the ATP7B gene is copper-transporting ATPase 2. The ATP7B gene has 57\% identity to the gene (fATP7A) defective in Menkes disease ${ }^{[14-16]}$. The protein is an intracellular transmembrane copper transporter that plays key roles in incorporating copper into ceruloplasmin and in moving copper out of the hepatocyte into bile. The protein is a P-type ATPase, characterized by cation channel and phosphorylation domains containing a highly conserved Asp-Lys-ThrGly-Thr (DKTGT) motif, in which the aspartate residue forms a phosphorylated intermediate during the transport cycle. The six copper-binding domains are similar to those found in yeast and bacteria $^{[17]}$. Eight hydrophobic regions span the cell membrane. Protein structure has been modeled based on a similar calcium transporting ATPase, SERVA1. The ATP7B gene is expressed mainly in liver and kidney.

The molecular basis for the observed phenotypic variation in patients with similar mutations to the ATP7B gene is not clear, but might result from environmental factors that include variability in nutritional copper intake. Modifier genes such as COMMD1 (also known as MURR1) - the gene responsible for canine WD - and ATOX1 might have a role in the sensing or trafficking function of the WD protein, and in patients with the apolipoprotein E3/3 genotype the onset of symptoms is sometimes delayed. Compound heterozygotes for the ATP7B mutation $^{[18-22]}$ are frequent in WD, which makes the genotype-phenotype correlation challenging. Frame shift deletions and nonsense mutations that cause a truncation of the translated protein product usually result in a severe form of the disease because of loss of the functional protein.

\section{Pathogenesis and Pathology}

WD is best appreciated with an understanding of copper metabolism. The body's basic daily copper requirement is about $1-2 \mathrm{mg}$, and this is met by dietary copper intake. Copper is needed by the body for a number of functions, predominantly as a cofactor for a number of enzymes such as ceruloplasmin, cytochrome c oxidase, dopamine $\beta$-hydroxylase, superoxide dismutase and tyrosinase.

Copper enters the body through the digestive tract. A transporter protein on the cells of the small bowel, copper mem- brane transporter 1 (CMT1), carries copper inside the cells, where some is bound to metallothionein and part is carried by ATOX1 to an organelle known as the trans-Golgi network. Here, in response to rising concentrations of copper, an enzyme called ATP7A releases copper into the portal vein to the liver. Liver cells also carry the CMT1 protein, and metallothionein and ATOX1 bind it inside the cell, but here it is ATP7B that links copper to ceruloplasmin and releases it into the bloodstream, as well as removing excess copper by secreting it into bile. Both functions of ATP7B are impaired in Wilson's disease. Copper accumulates in the liver issue; ceruloplasmin is still secreted, but in a form that lacks copper (termed apoceruloplasmin) and rapidly degraded in the bloodstream.

When the amount of copper in the liver overwhelms the proteins that normally bind it, it causes oxidative damage through a process known as Fenton chemistry; this damage eventually leads to chronic active hepatitis, fibrosis (deposition of connective tissue) and cirrhosis. The liver also releases copper into the bloodstream that is not bound to ceruloplasmin. This free copper precipitates throughout the body but particularly in the kidneys, eyes and brain. In the brain, most copper is deposited in the basal ganglia, particularly in the putamen and globus pallidus (together called the lenticular nucleus); these areas normally participate in the coordination of movement as well as playing a significant role in neurocognitive processes such as the processing of stimuli and mood regulation. Damage to these areas, again by Fenton chemistry, produces the neuropsychiatric symptoms seen in Wilson's disease.

The main areas of the brain affected in WD are the lenticular nuclei, which macroscopically appear brown in color because of copper deposition. Degeneration occurs with disease progression, leading to necrosis, gliosis and cystic changes, and lesions can be seen in the brainstem, thalamus, cerebellum and cerebral cortex. In the early stages of the disease, proliferation of large protoplasmic astrocytes such as Opalski cells and Alzheimer cells occurs. With disease progression, copper deposits lead to vacuolar degeneration in proximal renal tubular cells, causing 'Fanconi syndrome' and the appearance of the golden-brown 'Kayser-Fleischer' (KF) ring in Descemet's membrane in the cornea.Acute release of copper into the circulation can damage red blood cells, thereby inducing hemolysis. This is a characteristic finding observed in most cases of neurological Wilson's disease and approximately $50 \%$ of cases of hepatic Wilson's disease (Table 1).

\begin{tabular}{|c|c|c|c|c|c|c|}
\hline $\begin{array}{l}\text { Clinical } \\
\text { Presenta- } \\
\text { tion }\end{array}$ & $\%$ & $\begin{array}{l}\text { Typical age } \\
\text { of Presenta- } \\
\text { tion (Range) }\end{array}$ & $\begin{array}{l}\text { Liver } \\
\text { Dis- } \\
\text { ease }\end{array}$ & $\begin{array}{l}\text { Neuro- } \\
\text { logic } \\
\text { Disease }\end{array}$ & $\begin{array}{l}\text { Psychiat- } \\
\text { ric Distur- } \\
\text { bance }\end{array}$ & $\begin{array}{l}\text { Kayser- } \\
\text { Fleischer } \\
\text { Rings }\end{array}$ \\
\hline $\begin{array}{l}\text { Liver } \\
\text { Disease }\end{array}$ & $\sim 40 \%$ & $6-45(3-70)$ & + & $+/-$ & $+/-$ & $\sim 50 \%$ \\
\hline $\begin{array}{l}\text { Neuro- } \\
\text { logical } \\
\text { disease }\end{array}$ & $\sim 40 \%$ & $\begin{array}{l}\text { Mid-teen - } \\
\text { mid-adult } \\
(6-50)\end{array}$ & $\begin{array}{c}-/ \\
\text { Mild }\end{array}$ & + & $+/-$ & $\sim 90 \%$ \\
\hline $\begin{array}{l}\text { Psychiat- } \\
\text { ric distur- } \\
\text { bance }\end{array}$ & $\sim 20 \%$ & $\begin{array}{l}\text { Adoles- } \\
\text { cent-young } \\
\text { adult }\end{array}$ & $\begin{array}{c}-/ \\
\text { Mild }\end{array}$ & $+1-$ & + & $\sim 90 \%$ \\
\hline $\begin{array}{l}\text { Hem- } \\
\text { olitic } \\
\text { Anemia }\end{array}$ & $\begin{array}{c}\text { Few } \\
\%\end{array}$ & $\begin{array}{c}\text { Adoles- } \\
\text { cent-young } \\
\text { adult }\end{array}$ & + & - & - & + \\
\hline
\end{tabular}


The majority of patients with WD present with either predominantly hepatic or neuropsychiatric symptoms, and with either clinically asymptomatic or symptomatic liver involvement. The remaining $20 \%$ of patients, however, may present with symptoms attributable to the involvement of other organs.

\section{Signs and Symptoms}

The main sites of copper accumulation are the liver and the brain, and consequently liver disease and neuropsychiatric symptoms are the main features that lead to diagnosis. Patients with liver problems tend to come to medical attention earlier, generally as children or teenagers, than those with neurological and psychiatric symptoms, who tend to be in their twenties or older. Some are identified only because relatives have been diagnosed with Wilson's disease; many of these patients, when tested, turn out to have been experiencing symptoms of the condition but haven't received a diagnosis ${ }^{[23,24]}$.

\section{Hepatological Symptoms}

Hepatological symptoms present as tiredness increased bleeding tendency or confusion (due to hepatic encephalopathy) and portal hypertension. Typically symptoms will become apparent at around 6 years of age. The latter, a condition in which the pressure on the portal vein is markedly increased, leads to esophageal varices (blood vessels in the esophagus) that may bleed in a life-threatening fashion, splenomegaly (enlargement of the spleen) and ascites (accumulation of fluid in the abdominal cavity). On examination, signs of chronic liver disease such as spider naevi (small distended blood vessels, usually on the chest) may be observed. Chronic active hepatitis has caused cirrhosis of the liver (Figure 2) in most patients by the time they develop symptoms. While most people with cirrhosis have an increased risk of hepatocellular carcinoma (liver cancer), this risk is relatively very low in Wilson's disease.

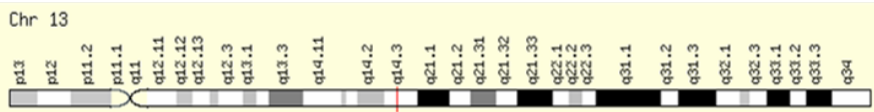

Figure 2: Location of the gene ATP7B on Chromosome 13

About $5 \%$ of all patients are diagnosed only when they develop fulminant acute liver failure, often in the context of a hemolytic anemia (anemia due to the destruction of red blood cells). This leads to abnormalities in protein production (identified by deranged coagulation) and metabolism by the liver. The deranged protein metabolism leads to the accumulation of waste products such as ammonia in the bloodstream. When these irritate the brain, the patient develops hepatic encephalopathy (confusion, coma, seizures and finally life-threatening swelling of the brain).

\section{Neuropsychiatric symptoms}

About half the patients with Wilson's have neurological or psychiatric problems (Figure 3). Most patients initially have mild cognitive deterioration and clumsiness, as well as changes in behavior. Specific neurological symptoms then follow, often in the form of Parkinsonism (increased rigidity and slowing of routine movements) with or without a typical hand tremor, ataxia (lack of coordination) or dystonia (twisting and repetitive movements of part of the body). Seizures and migraine appear to be more common in Wilson's disease ${ }^{[25]}$. Psychiatric problems due to Wilson's disease may include behavioral changes, depression, anxiety and psychosis.

Figure 3: Wilson's disease patient showing Neuropsychiatric symptoms

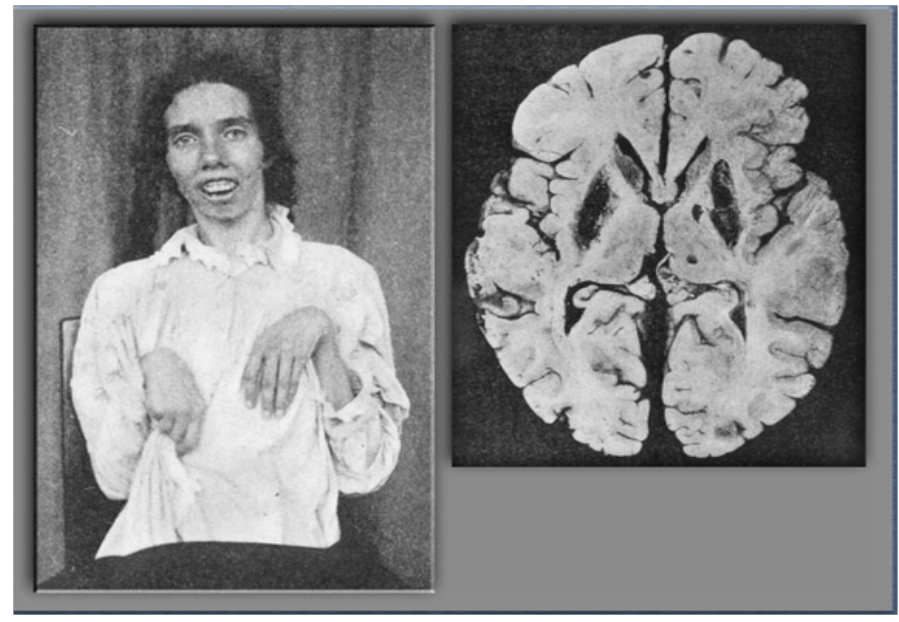

\section{Biochemical Investigations}

Biochemical testing is used in support of the diagnosis of Wilson disease. The biochemical diagnosis in a symptomatic individual relies upon demonstration of abnormal copper parameters. A combination of any two of the following three findings (1-3) is strong support for a diagnosis of Wilson disease ${ }^{[26]}$.

\section{Low serum ceruloplasmin concentration:}

In children, interpretation of test results requires age correction or age-specific reference ranges.

Note: Healthy newborns have low serum ceruloplasmin concentrations. The concentrations increase during the first six months of life and by two to three years of age peak at a concentration that may exceed the healthy adult reference range.

In adults with Wilson disease, serum ceruloplasmin concentration is often below the normal range and typically very low. Note: A normal serum ceruloplasmin concentration is found in at least $5 \%$ of individuals with Wilson disease with neurologic symptoms and up to $40 \%$ of individuals with hepatic symptoms. Serum ceruloplasmin concentration is, therefore, not a reliable screening test for Wilson disease.

High urinary copper: Measurement of copper in three 24-hour urine collections, free from contamination by external sources of copper, is advised. The testing laboratory should be consulted regarding its trace-element urine collection protocol prior to initiating urine specimen collection. Basal urinary copper excretion (without the use of chelating agent) is almost invariably elevated above $0.6 \mu \mathrm{mol} / 24$ hours in the symptomatic individual. A provocative test of urinary copper excretion following oral administration of penicillamine is useful in many cases, although levels in affected individuals can overlap with those of heterozygotes.

Increased hepatic copper concentration: Hepatic copper concentration in Wilson disease is usually greater than $250 \mu \mathrm{g} / \mathrm{g}$ dry 
weight (normal: $<55 \mu \mathrm{g} / \mathrm{g}$ dry weight; however, such levels may be seen in other chronic liver disorders as well.

Note: (1) In later stages of Wilson disease, copper is distributed unevenly in the liver and measurement of hepatic copper concentration is less reliable. (2) Some individuals have only a moderately elevated hepatic copper concentration - 100 to $250 \mu \mathrm{g} / \mathrm{g}$ dry weight, which overlaps with values occasionally found in heterozygotes. Thus, hepatic copper concentration in this range does not exclude the diagnosis of Wilson disease.

\section{Slit-Lamp Examination}

Kayser-Fleischer rings (KF rings) may be visible around the iris. Slit-lamp examination of the cornea for Kayser-Fleischer rings should be performed by an experienced ophthalmologist.Kayser-Fleischer rings are present in virtually every patient with neurologic disease,but may be absent in younger patients with hepatic manifestations only.

\section{Neuroimaging}

Imaging plays an important role in both the diagnosis of WD and the monitoring of patients during therapy. Brain CT scans are relatively insensitive, but can reveal hypodensities and atrophy of the bilateral basal ganglia, brainstem, cerebellum and cerebral cortex (Figure 4). MRI is a very sensitive method for revealing abnormalities in WD. On T1-weighted images, generalized brain atrophy is seen in three-quarters of cases, and hypointensities in the basal ganglia in two-thirds of cases ${ }^{[27-29]}$. On T2-weighted images, one-third of cases demonstrate hyperintensity in the basal ganglia, white matter, thalamus or brainstem. These abnormalities are caused by neuronal loss, gliosis, degeneration of fibers, and vacuolization associated with increased water content in the brain. Signal abnormalities vary according to the stage of the disease, and can be reversible with therapy in the early stages.

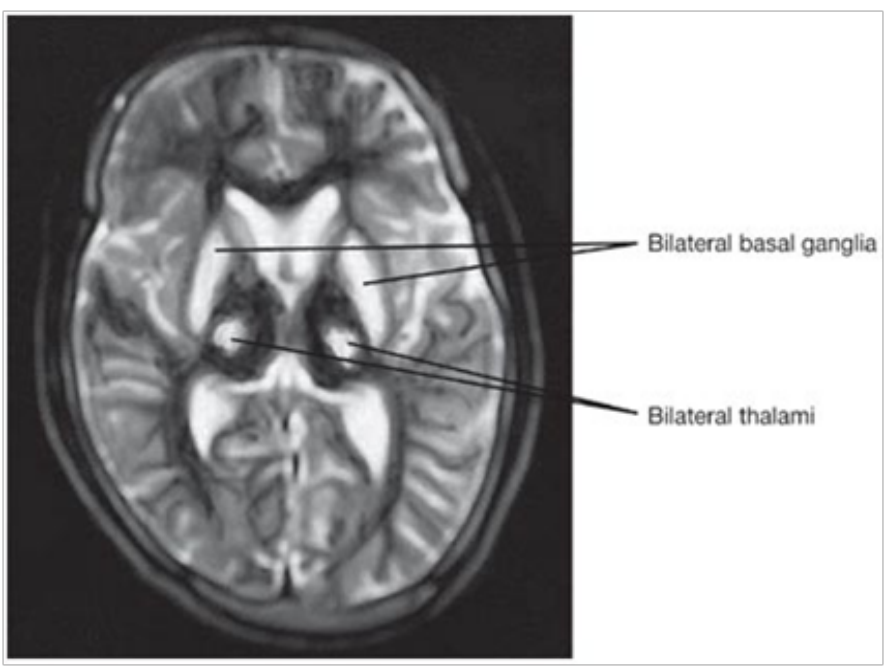

Figure 4: Hyperintensities in the bilateral basal ganglia and thalami shown by T2-weighted MRI of the brain.

Some WD-related changes exhibit characteristic features on MRI, for instance 'face of the giant panda', which is seen in T2-weighted images of the midbrain ${ }^{[30]}$ and 'face of the miniature panda', which can be seen in the tegmentum region of the pons in the same sequence. Sometimes, T2-weighted imag- es show hypointensity in the basal ganglia region as a result of deposition of iron in exchange for copper after chelation. MRI findings can be similar to those seen in several other disorders, including Leigh disease, hypoxic-ischemic encephalopathy, methyl alcohol poisoning, Japanese B encephalitis, and selective extrapontine myelinolysis caused by osmotic disequilibrium syndrome. It is essential, therefore, to correlate the imaging with clinical features and biochemical markers of $\mathrm{WD}^{[31-39]}$.

Proton magnetic resonance spectroscopy (MRS) provides noninvasive information about the biochemistry of a defined volume of brain. In WD, N-acetylaspartate (NAA):creatine and choline:creatine ratios are reduced. To determine the abnormality in MRS analysis, it is important to compare the results with those from a control person. One MRS report on patients with WD found the mean NAA:creatine ratio to be 1.30 0.40 , the mean NAA:choline ratio to be 1.430 .45 , and the mean choline:creatine ratio to be 0.960 .34 , compared with control values of NAA:creatine $-1.60 \quad 0.34$, NAA:choline - $1.83 \quad 0.44$, and choline:creatine -0.89 0.12(Alanen A etal(1999). As creatine is relatively stable and is present in the glial cells that are least affected in WD, a reduction in both the choline:creatine and NAA:creatine ratios is indicative of a loss of neurons. In hepatic WD, these ratios remain normal, thus helping to distinguish primary brain involvement in WD from hepatic encephalopathy.

MRS has shown decreased levels of myo-inositol in patients with portosystemic shunting, which is usually a secondary consequence of portal hypertension in hepatic D. PET scans have shown a decrease in dopamine transporter function and in D2 receptors in the striatum ${ }^{[40]}$.

\section{Genetic Investigation}

The use of mutation screening to identify defects in the ATP7B gene can provide unequivocal confirmation of WD in an affected symptomatic or presymptomatic individual. Because of the large size of the gene, however, and the potential for a mutation anywhere along its entire length, identification of mutations is very challenging. Identification of the prevalent mutations in a given population is therefore desirable in order to provide direct mutation-based molecular diagnosis for a larger segment of the affected population. Progress in the diagnosis of WD has been made by studying microsatellite markers flanking the ATP7B gene and using linkage analysis to elucidate disease transmission in siblings of affected individuals. Marker-based diagnosis should be undertaken when the specific defect in the ATP7B gene is not known ${ }^{[30]}$.

With a diagnosis of $\mathrm{WD}$, it is mandatory to counsel family members on the importance of biochemical or genetic screening of siblings and other family members, to identify those who might be presymptomatic gene mutation carriers. Monitoring of the presymptomatic individual and placement on a treatment regimen before the onset of clinical symptoms can then be carried out as appropriate. The probability of family members of an affected individual being similarly affected (carrying two mutated genes) is $25 \%$ for siblings and $0.5 \%$ for offspring. For prenatal screening, both linkage and mutational analysis is needed(Table 2). 
Table 2: Screening Family Members of Patients with Wilson's Disease

\begin{tabular}{|c|c|c|c|c|}
\hline \multirow{2}{*}{ Tests } & \multicolumn{2}{|c|}{$\begin{array}{l}\text { Homozygous or compound } \\
\text { heterozygous }\end{array}$} & \multirow{2}{*}{$\begin{array}{l}\text { Heterozy- } \\
\text { gous carrier }\end{array}$} & \multirow{2}{*}{$\begin{array}{c}\text { Non-car- } \\
\text { rier }\end{array}$} \\
\hline & Symptomatic & $\begin{array}{l}\text { Presymp- } \\
\text { tomatic }\end{array}$ & & \\
\hline $\begin{array}{l}\text { Clinical Ex- } \\
\text { amination }\end{array}$ & $\begin{array}{l}\text { Might have ei- } \\
\text { ther early hepatic } \\
\text { or neurological } \\
\text { features }\end{array}$ & $\begin{array}{l}\text { Hepatomeg- } \\
\text { aly in } 38 \% \\
\text { of cases }\end{array}$ & $\begin{array}{l}\text { No apparent } \\
\text { Clinical } \\
\text { abnormality }\end{array}$ & Normal \\
\hline $\begin{array}{l}\text { Slit lamp } \\
\text { Examination } \\
\text { for KF ring }\end{array}$ & $\begin{array}{l}\text { Commonly } \\
\text { positive in } \\
\text { neuropsychiatric } \\
\text { presentations and } \\
\text { in } 50 \% \text { of hepat- } \\
\text { ic presentation }\end{array}$ & $\begin{array}{l}\text { Positive KF } \\
\text { ring in about } \\
1 / 3 \text { of cases }\end{array}$ & $\begin{array}{l}\text { Usually } \\
\text { Negative }\end{array}$ & Negative \\
\hline $\begin{array}{l}\text { Serum } \\
\text { ceruloplas- } \\
\text { min level }\end{array}$ & $\begin{array}{l}\text { Low in about } \\
85 \% \text { of cases }\end{array}$ & $\begin{array}{l}\text { Same as } \\
\text { Symptom- } \\
\text { atic }\end{array}$ & $\begin{array}{l}\text { Low }(<15 \\
\mathrm{mg} \%) \text { in } \\
\text { About } 15- \\
20 \% \text { of cases }\end{array}$ & Normal \\
\hline $\begin{array}{l}\text { Genetic } \\
\text { Analysis } \\
\text { (haplotypic) }\end{array}$ & $\begin{array}{l}\text { Mutation in both } \\
\text { Wilson's disease } \\
\text { genes }\end{array}$ & $\begin{array}{l}\text { Same as } \\
\text { Symptom- } \\
\text { atic }\end{array}$ & $\begin{array}{l}\text { Abnormal } \\
\text { mutation in } \\
\text { one gene }\end{array}$ & $\begin{array}{l}\text { No Mu- } \\
\text { tational } \\
\text { change }\end{array}$ \\
\hline $\begin{array}{l}\text { 24-hour uri- } \\
\text { nary copper } \\
\text { excretion } \\
(20-50 \mu \mathrm{g})\end{array}$ & $\begin{array}{l}\text { Usually high } \\
(>100 \mu \mathrm{g})\end{array}$ & $\begin{array}{l}\text { Same as } \\
\text { Symptom- } \\
\text { atic }\end{array}$ & Normal & Normal \\
\hline $\begin{array}{l}\text { Neuroimag- } \\
\text { ing of Brain }\end{array}$ & $\begin{array}{l}\text { Commonly } \\
\text { abnormal in } \\
\text { neuropsychiatric } \\
\text { presentation }\end{array}$ & $\begin{array}{l}\text { Abnormal } \\
\text { in } 25 \% \text { of } \\
\text { cases }\end{array}$ & Normal & Normal \\
\hline
\end{tabular}

\section{Treatment and Management}

\section{Medical therapy}

The aim of medical treatment for WD is to remove the toxic deposit of copper from the body to produce a negative copper balance, and to prevent its reaccumulation. Successful therapy is measured in terms of a restoration of normal levels of free serum copper and its excretion in the urine.

Copper chelating agents are the first-line therapy for WD. In the initial phase of treatment, toxic levels of copper are controlled, and dietary copper is restricted. Patients should avoid copper-rich food such as chocolate, nuts, shellfish and liver, and abstain from cooking or taking food from copper bowls and plates. The average daily diet contains $2-4 \mathrm{mg}$ of copper, and 0.8 $\mathrm{mg}$ of copper is normally lost through the feces each day. Chelating agents are therefore prescribed to promote 24-hour excretion of approximately $2 \mathrm{mg}$ of copper in the urine, to induce a negative copper balance. In the maintenance phase, the dosage can be reduced and zinc salt added to prevent the systemic absorption of copper. Studies have demonstrated that the majority of presymptomatic WD patients treated indefinitely with either zinc or copper chelators achieve a successful outcome. Since 1955, D-penicillamine ${ }^{[41]}$ has been the most commonly used chelating agent, and an animal model of WD has demonstrated its efficacy as a chelator.Other chelating agents that can be used include triethylene tetramine dihydrochloride (trientine). In addition, zinc salt (sulfate or acetate) helps in the prevention of copper absorption from the gut ${ }^{[42]}$.

D-penicillamine not only chelates copper from tissue, but also detoxifies tissue copper by promoting the synthesis of metallothionein, which forms a non-toxic combination with copper. During administration of D-penicillamine, periodic clinical, hematological, biochemical (transaminases) and routine urinary parameters are monitored weekly for 1 month, then monthly for 6 months and at 6-monthly intervals thereafter. An improvement in clinical features is usually noted after $2-3$ months, continuing over a period of 1-2 years. Regular measurement of the 24-hour urinary excretion of copper provides an important index of copper removal from the body. If the excretion level in a compliant patient decreases to less than $0.5 \mathrm{mg}$ daily, the dose can be lowered. At this point, a zinc salt should be added to the treatment regimen, preferably before meals. D-penicillamine should be taken 2 hours after meals to avoid any interaction with the zinc. Side effects from D-penicillamine can occur both early and late in the treatment period. Early side effects include a hypersensitivity reaction characterized by fever, skin rash and lymphadenopathy that commonly occurs within 3 weeks of commencing medication. In $20-30 \%$ of cases, an exacerbation of the neurological symptoms occurs over a period of 2 weeks to 12 months (commonly after 6 weeks). This occurrence is caused by the rapid mobilization of liver copper in the circulation, and can sometimes be permanent. An early hypersensitivity reaction can be managed by temporary withdrawal of the drug, followed by its reintroduction after a course of oral steroids. Neurological deterioration can be attenuated by withdrawing the drug, and then reinstituting it at a smaller dosage with a slow escalation to the optimum dosage. If neurological deterioration recurs, D-penicillamine should be withdrawn and substituted with other chelators or zinc salt alone .Pyridoxine (vitamin B6) is added routinely to the treatment regimen in a dosage of $25-50 \mathrm{mg}$ daily, as its deficiency has been documented during D-penicillamine therapy. Delayed side effects occur in about $5 \%$ of cases, and can be caused by immunological factors, interference with collagen and elastin synthesis, or idiopathic factors. Immunological side effects are managed with steroids and a reduction in the D-penicillamine dosage. In cases in which the patient cannot tolerate treatment with D-penicillamine, trientine can be used as a substitute, which is usually effective except in cases with systemic lupus erythematosus or elastosis perforans.

Trientine and ammonium tetrathiomolybdate ${ }^{[42]}$ are considered to be safer alternatives to D-penicillamine. Trientine is a less potent copper remover than D-penicillamine, and its toxic profile is similar to that of D-penicillamine, although side effects are less frequent and generally milder. Ammonium tetrathiomolybdate, an agent previously used to treat copper toxicosis in animals, has been advocated because of its lower toxic profile, but it is still an experimental drug that is not routinely available, and its long-term safety and efficacy is unknown.

Pregnant women with WD can have a successful pregnancy while undergoing chelation therapy. These patients should continue on the same agent but with a slightly reduced dosage, particularly in the third trimester. Abrupt cessation of the drug treatment can be fatal. If the patient is completely free of toxic copper, she he should be advised to take only zinc salt. Although D-penicillamine and trientine are potentially teratogenic, there are currently insufficient data concerning their teratogenic effects in pregnant patients with WD to warrant cessation of 
treatment.

\section{Symptomatic Treatment}

Symptomatic treatment for dystonia and parkinsonian features, psychiatric disturbances, and encephalopathy can be very successful and reassuring for the patient with WD. The treatment of dystonia and parkinsonian features includes the administration of anticholinergics, tizanidine, baclofen, levodopa, or -aminobutyric acid (GABA) agonists - particularly clonazepam. Comparative studies of the use of these medications for symptomatic therapy are, however, lacking. Botulinum toxin injection is a useful adjunct therapy in cases with severe limb dystonias when other treatments are unsuccessful. Convulsions can be controlled with both traditional and newer antiepileptic drugs. In an opinion, more than one drug is often required to achieve control. Psychiatric disturbance is usually managed with atypical neuroleptics, and occasionally with traditional neuroleptics. Hepatic encephalopathy is managed with a standard regimen of protein restriction and lactulose ${ }^{[43-46]}$.

\section{Hepatic Transplantation}

In patients with progressive liver failure or acute liver failure from fulminant hepatitis with or without intravenous hemolysis, orthotropic hepatic transplantation is an efficient treatment, and can reverse the abnormal pathology mediated by the liver in patients with WD. Hepatic transplantation is also indicated in the absence of liver failure in patients with neurological WD in whom chelation therapy has proved ineffective, and significant improvements in neurological features have been reported, which include the disappearance of the KF ring.

\section{Materials and Methods}

\section{Materials}

A total no of 20 control and 20 samples of patients were studied for mutations in exon 8 of ATPase gene.

\section{Methods}

1. Collection of blood

2. Isolation of DNA

3. Pcr

4. Agarose Gel Electrophoresis

5. Rflp

1. Collection of blood: $5 \mathrm{ml}$ of peripheral blood was taken in a vacutainer containing 2 drops of $0.5 \mathrm{M}$ EDTA by using $5 \mathrm{ml}$ syringes.

2. Extraction of DNA: DNA was isolated according to modified Blin and Stafford (1976) method.

\section{Chemicals Required}

Erythrocyte Lysis Buffer: It consists of-

- $\quad 8.3 \mathrm{gms}$ of Ammonium Chloride (155mM)

- $\quad 1.0 \mathrm{gm}$ of Potassium Carbonate (7.23mM or $0.007 \mathrm{M})$

- $\quad 200 \mu 1$ of $\operatorname{EDTA}(0.5 \mathrm{~m})$

- $\mathrm{pH}$ was adjusted to7.5.

20\%SDS: $20 \mathrm{mg}$ of Sodium Dodecyl Sulphate was dissolved in $100 \mathrm{ml}$ of autoclaved water.

Proteinase K: $20 \mathrm{mg}$ of Proteinase K was dissolved in $1 \mathrm{ml}$ of water.
Phenol: Phenol was saturated with equal volume of Tris- $\mathrm{HCl}$ until a $\mathrm{pH}$ of 8 was obtained.

Chloroform-Isoamyl alcohol: Chloroform and Isoamyl alcohol were mixed in 24:1 ratio.

Absolute Alcohol: 100\% alcohol serves as absolute alcohol.

TE Buffer: $10 \mathrm{mM}$ tris and 1mM EDTA (PH 8.0) will be used as TE buffer.

TE buffer for $100 \mathrm{ml}$ consists of-

- Tris $10 \mathrm{mM}-1 \mathrm{ml}$

- EDTA $0.1 \mathrm{mM}-20 \mu 1$

Make up the volume to $100 \mathrm{ml}$ with distilled water.

Procedure

1. Take $5 \mathrm{ml}$ of blood sample in an EDTA vacutainer.

2. Add 3 times equal volume of Erythrocyte Lysis Buffer (ELB)

to the blood sample and shake it for 5 minutes.

3 . Keep it in ice for 15 minutes.

4. Remove the tubes from ice and spin at $4500 \mathrm{rpm}$ for $10 \mathrm{~min}$ utes in cool centrifuge set at $-4^{\circ} \mathrm{C}$

5. Discard the supernatant; disturb the pellet with $1 \mathrm{ml}$ of ELB make upto $5 \mathrm{ml}$ with ELB.

6. Repeat the step 2-5 until a pale colored pellet is obtained.

7. Add $300 \mu \mathrm{l}$ of $20 \%$ SDS, mix gently 3 to 4 minutes.

8. Add $40 \mu \mathrm{l}$ of protinase $\mathrm{K}$; incubate in water bath set at $37^{\circ} \mathrm{C}$ overnight.

9. After overnight incubation add $5 \mathrm{ml}$ of phenol to the sample and mix slowly. Spin at 10,000 rpm for 10 minutes at $4^{\circ} \mathrm{C}$.

10. Transfer the upper layer of supernatant in afresh autoclaved tube.

11. To this add $5 \mathrm{ml}$ equal volume of phenol chloroform- Isoamyl Alcohol, mix gently and spin at 10,000rpm for 10 minutes.

12. Transfer the upper layer of supernatant into another fresh autoclaved tube and add $5 \mu \mathrm{l}$ of Chloroform, spin at 10,000rpm for 10 minutes.

13. Collect the supernatant in another tube and add chilled $100 \%$ Ethanol.

14. Precipitated DNA was observed, keep the tubes at $-20^{\circ} \mathrm{c}$ overnight.

15. Transfer the DNA to $1.5 \mathrm{ml}$ eppendorf and 3 washes with $70 \%$ ethanol was done.

16. After drying, add TE buffers $(150-200 \mathrm{ml})$ incubate at $65^{\circ} \mathrm{c}$ for 1 hour.

17. Store the DNA at $-20^{\circ} \mathrm{c}$ for further analysis.

\section{Polymerase Chain Reaction}

PCR requires the following for a sample $(50 \mu \mathrm{L})$ :

1. Forward primer $-1 \mu \mathrm{L}$

2. Reverse primer $-1 \mu \mathrm{L}$

3. Buffer $-5 \mu \mathrm{L}$

4. dNTP mix $-1 \mu \mathrm{L}$

5. Taq DNA Polymerase $-0.5 \mu \mathrm{L}$

6. DNA sample $-1 \mu \mathrm{L}$

7. Distilled water $-40.5 \mu \mathrm{L}$

Procedure for calculating Annealing temperature for PCR:

1. Calculate the number of Adenine and Thymidine bases in Forward primer sequence and multiply with 2 . Calculate the number of Guanine and Cytosine in forward sequence and multiply with 4. Sum the two.

2. Calculate the number of Adenine and Thymidine bases in Re- 
verse primer sequence and multiply with Calculate the number of Guanine and Cytosine in forward sequence and multiply with 4. Sum the two.

3. Calculate the total number of AT and GC in forward and reverse sequences combined. Sum the two.

4. Find out the average of the sum.

5 . Subtract 5 from this number.

The resulting is the annealing temperature calculated from the two primers specified for exon 8 .

Forward primer - 5' TCC CTA CTT GCT GGC AGC 3'

Reverse primer - 5' AAA CAT GGT GTT CAG AGG AAG TG 3'

$=62^{\circ} \mathrm{C}$

PCR involves the following the cycling reactions: There are three major steps in a PCR, which are repeated for 30 cycles (Figure 5). This is done on an automated thermal cycler (Bio Rad Technologies), which can heat and cool the tubes with the reaction mixture in a very short time.

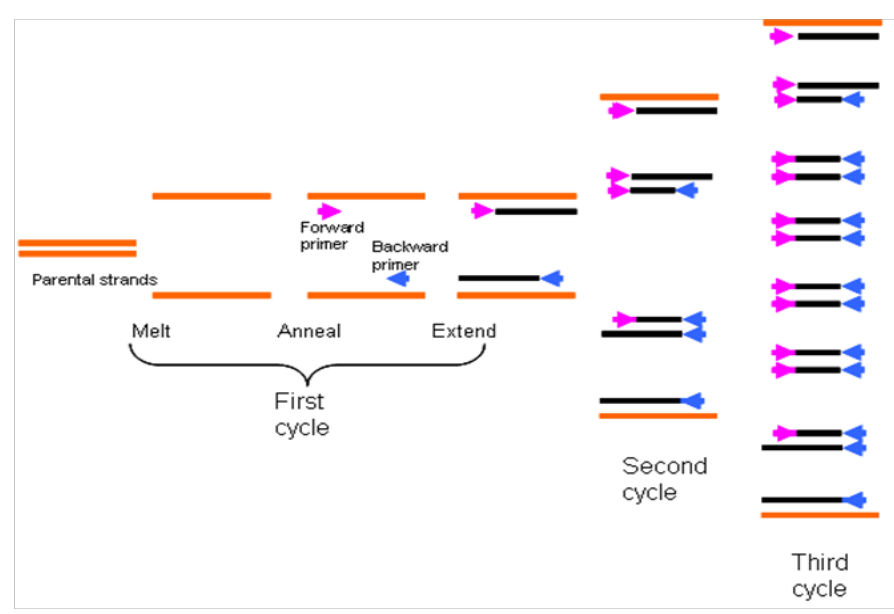

Figure 5: The different steps in PCR.

Denaturation at $95^{\circ} \mathrm{C}$ : During the denaturation (Figure 5), the double strand melts open to single stranded DNA, all enzymatic reactions stop (for example: the extension from a previous cycle).

Annealing at $69^{\circ} \mathrm{C}$ : The primers are jiggling around, caused by the Brownian motion. Ionic bonds are constantly formed and broken between the single stranded primer and the single stranded template. The more stable bonds last a little bit longer (primers that fit exactly) and on that little piece of double stranded DNA (template and primer), the polymerase can attach and starts copying the template. Once there are a few bases built in, the ionic bond is so strong between the template and the primer, that it does not break anymore.

Extension at $72^{\circ} \mathrm{C}$ : This is the ideal working temperature for the polymerase. The primers, where there are a few bases built in, already have a stronger ionic attraction to the template than the forces breaking these attractions. Primers that are on posi- tions with no exact match get loose again (because of the higher temperature) and don't give an extension of the fragment.

The bases (complementary to the template) are coupled to the primer on the 3' side (the polymerase adds dNTP's from 5' to 3', reading the template from 3' to 5' side, bases are added complementary to the template).

Because both strands are copied during PCR, there is an exponential increase of the number of copies of the gene. Suppose there is only one copy of the wanted gene before the cycling starts, after one cycle, there will be 2 copies, after two cycles, there will be 4 copies, three cycles will result in 8 copies and so on.

Gel Electrophoresis of DNA: Agarose gel electrophoresis is a method used in biochemistry and molecular biology to separate DNA, or RNA molecules by size. This is achieved by moving negatively charged nucleic acid molecules through an agarose matrix with an electric field (electrophoresis). Shorter molecules move faster and migrate farther than longer ones. The purpose of the gel might be to look at the DNA, to quantify it or to isolate a particular band. The DNA is visualized in the gel by addition of ethidium bromide. This binds strongly to DNA by intercalating between the bases and is fluorescent meaning that it absorbs invisible UV light and transmits the energy as visible orange light. Buffer: TBE or Tris/Borate/EDTA, is a buffer solution containing a mixture of Tris base, boric acid and EDTA. In molecular biology, TBE buffer is often used in procedures involving nucleic acids, the most common being electrophoresis. Tris-acid solutions are effective buffers for slightly basic conditions, which keep DNA deprotonated and soluble in water. EDTA is a chelator of divalent cations, particularly of magnesium $\left(\mathrm{Mg}^{2+}\right)$. As these ions are necessary co-factors for many enzymes, including contaminant nucleases, the role of the EDTA is to protect the nucleic acids against enzymatic degradation. But since $\mathrm{Mg}^{2+}$ is also a co-factor for many useful DNA-modifying enzymes such as restriction enzymes and DNA polymerases, its concentration in TBE or TAE buffers is generally kept low (typically at around $1 \mathrm{mM})$. Generally, TBE Buffer solution 1.0x, $\mathrm{pH} 8.0$ is made.

\section{Preparation of the Gel:}

- Make a $2 \%$ agarose solution in $50 \mathrm{~mL}$ TBE $(1$ gram in $50 \mathrm{~mL}$ of TBE buffer), for typical DNA fragments. A solution of up to $2-4 \%$ can be used if you analyze small DNA molecules, and for large molecules, a solution as low as $0.7 \%$ can be used.

- Carefully bring the solution just to the boil to dissolve the agarose.

- Let the solution cool down to about $60{ }^{\circ} \mathrm{C}$ at room temperature, or water bath. Stir or swirl the solution while cooling.

- Add $2 \mu \mathrm{L}$ Ethidium bromide (stock) per $50 \mathrm{~mL}$ gel solution, Instead of this we can also soak the gel in an ethidium bromide solution after running.

- Insert the comb at one side of the gel, about 5-10 $\mathrm{mm}$ from the end of the gel.

- Stir the solution to disperse the ethidium bromide, and then pour it into the gel rack.

- When the gel has cooled down and become solid, carefully remove the comb. The holes that remain in the gel are the wells 
or slots.

- Put the gel, together with the rack, into a tank with TBE.

\section{Procedure}

After the gel has been prepared, use a micropipette to inject about $10 \mu \mathrm{L}$ of stained DNA and, for sizing a ladder is added. Close the lid of the electrophoresis chamber and apply current (typically $100 \mathrm{~V}$ for 30 minutes with $50 \mathrm{~mL}$ of gel). A color marker dye containing a low molecular weight dye such as "Bromophenol blue" in the DNA ladder and DNA samples acts as a "front wave" that runs faster than the DNA itself. When the "front wave" approaches the end of the gel, the current is stopped. The DNA is stained with ethidium bromide, and is then visible under ultraviolet light.

\section{Restriction Fragment Length Polymorphism (RFLP)}

A molecular method of genetic analysis that allows individuals based on unique patterns of restriction enzymes cutting in specific regions of DNA. The term polymorphism refers to the slight differences between individuals, in base pair sequences of common genes. Even though all members of a species have essentially the same genetic makeup, these slight differences account for variations in phenotype (i.e. appearance, metabolism etc.) between individuals.

RFLP methodology involves cutting a particular region of DNA with known variability, with restriction enzymes, then separating the DNA fragments by agarose gel electrophoresis and determining the number of fragments and relative sizes. The pattern of fragment sizes will differ for each individual tested. The resulting fragments of DNA are loaded on to an agarose gel, which separates fragments according to molecular size. After the completion of run gel is viewed under gel documentation system.

The banding pattern on the gel can be used to draw conclusions on the number and position of restriction sites. Differences result from base substitutions, deletions, additions or sequence rearrangements within $\mathrm{RE}$ recognition sequences. The frequencies of individual banding patterns in a population and the difference between them can be used to estimate genetic diversity and differentiation between populations

The amplified DNA by PCR was subjected to restriction digestion using the following enzyme: Hpa II-Haemophilus parainfluenzae II.

\section{RFLP Mixture}

1. PCR product: $10 \mu \mathrm{L}$

2. Tango Buffer : $2 \mu \mathrm{L}$

3. Restriction Enzyme: $0.5 \mu \mathrm{L}$

4. Distilled Water: $7.5 \mu \mathrm{L}$

Total: $20 \mu \mathrm{L}$

Temperature: $37^{\circ} \mathrm{C}$

Time: 12 Hours.

\section{Results}

A total no of 20 control and 20 patient samples were studied for mutations in exon 8 of ATP7B gene.

1. Extraction of DNA: DNA was extracted from the samples by Phenol-Chloroform method and was analyzed by Agarose Gel Electrophoresis (Figure 6)

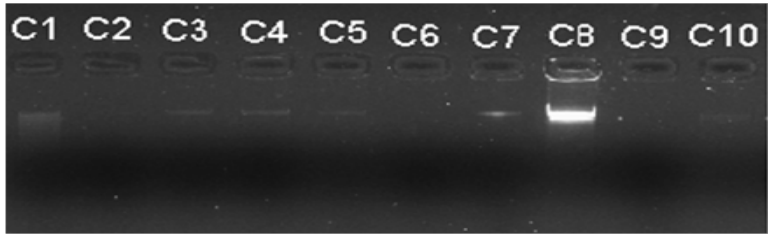

Figure 6: Gel Electrophoresis image of control samples DNA check run.

2. Standardization of DNA at different temperatures by PCR and the band with good intensity resulted at $62^{\circ} \mathrm{C}$ (Figure 7).

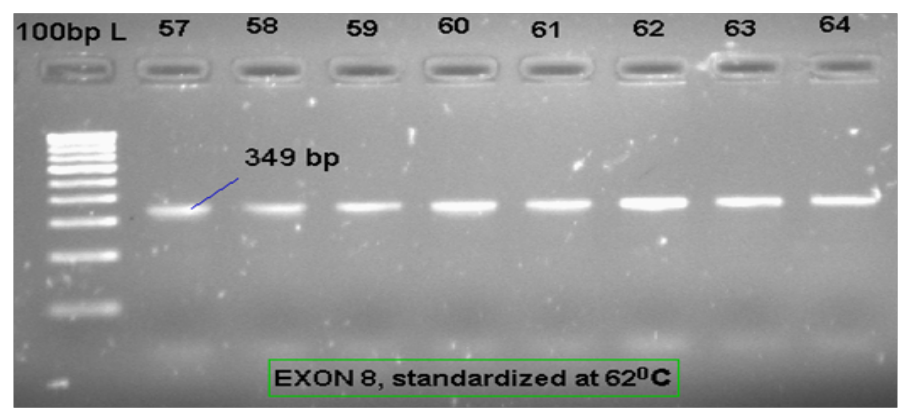

Figure 7: Gel Electrophoresis image of control samples DNA check run which shows the band standardized at $62^{\circ} \mathrm{C}$.

3. PCR for Exon 8 at $62^{\circ} \mathrm{C}$ and compared with 100 base pair ladder (Figure 8).

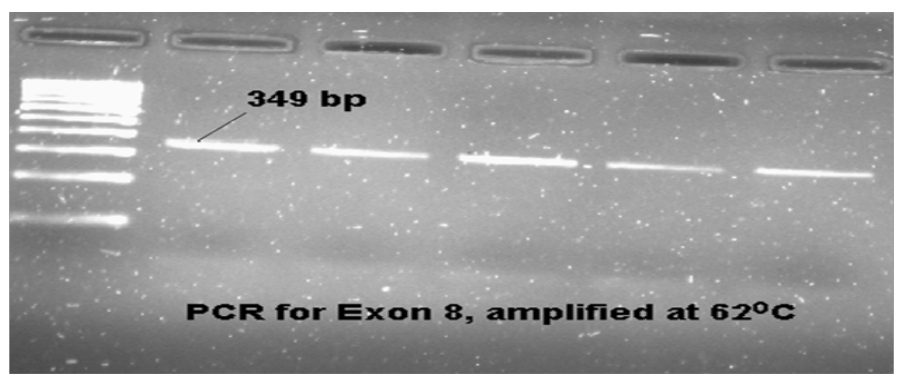

Figure 8: PCR product of 349 bp amplified for control samples in comparison with $100 \mathrm{bp}$ ladder.

4. RFLP for exon 8 using the enzyme Hpa II resulting in Homozygotes (Figure 9).

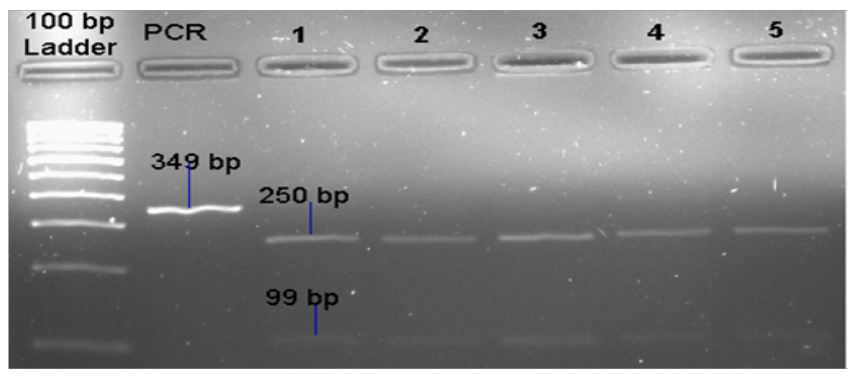

Figure 9: The above image shows the enzyme Haemophilus parainfluenzae II 
cutting the DNA of 349 bp into $250 \mathrm{bp}$ and $99 \mathrm{bp}$. All the patient samples were normal i.e., wild showing no mutations in exon

\section{Discussion}

Wilson's disease is an autosomal recessive disorder. It is caused by mutations to the gene coding for ATPase copper transporting beta polypeptide (ATP7B), which is located on chromosome 13. There are 21 exons in ATPase gene of Wilson's disease, most common mutations are observed in $2,5,8,14 \& 15$ exons.

In India, mutations in exon 8 are more frequently observed. Arg778Leu, Arg778Gln \& His1069Glu are the frequently observed mutations in exon 8. Restriction enzyme used for anaslysis is Hpa II which cuts evenly and gives 2 bands for normals viz.,250 bp and 99 bp , homozygous (mutant) shows viz. 349 bp \& heterozygote shows both normal \& mutant bands(i.e., $349 \mathrm{bp}, 250 \mathrm{bp}$ and $99 \mathrm{bp}$ ).

In this pilot study, a total no of 20 control samples were studied for screening mutations in exon 8 of ATPase gene. For this, DNA was isolated by Phenol Chloroform method and amplified using specific primers. Finally PCR product was subjected to restriction digestion (RFLP).

Inference: DNA isolated from 20 control samples were subjected to restriction analysis by using the restriction enzyme Hpa I I. The digested products of $349 \mathrm{bp}$ have resulted in the products of $250 \mathrm{bp}$ and $99 \mathrm{bp}$ size. The inference from the restriction analysis shows that all the control samples are normal. They have not resulted in any mutation[47-49].

\section{Conclusion}

The DNA isolated from samples by Phenol Chloroform method were subjected to amplification by polymerase chain reaction. The amplified DNA was digested by RFLP technique using restriction enzyme Hpa II.

Since this is a pilot study with only 20 samples no mutations were observed in exon 8 . The status of the mutations with relation to the disease should be studied in much larger population size to arrive at a better conclusion.

Acknowledgements: The results of the study presented in this dissertation work is original and carried out by me under the supervision of Dr. M.Sujatha, Institute of Genetics and Hospital for Genetic Diseases, Osmania University, Hyderabad. This work has not been submitted for the award of any degree or diploma in part or full prior to this date.

\section{References}

1. Kinnier Wilson, S.A. Progressive lenticular degeneration: a familial nervous disease associated with cirrhosis of the liver. (1912) Brain 34 (4): 295-507.

2. Cumings, J.N. The copper and iron content of brain and liver in the normal and in hepato -lenticular degeneration. (1948) Brain 71(4): 410415 .

3. Atsushi I. Asymmetry of Symptoms and Signs in Multiple System Atrophy (2014)Int J Neurol Brain Disord 1(1): 1-2.

4. Frommer, D.J. Defective biliary excretion of copper in Wilson's disease. (1974) Gut 15(2): 125-129.

5. Scheinberg, I.H., Gitlin, J.D. Deficiency of ceruloplasmin in patients with hepatolenticular degeneration (Wilson's disease). (1952) Science 116(3018): $484-485$.

6. Bull, P.C., Thomas, G.R., Rommens, J.M., et,al. The Wilsons disease gene is a putative copper transporting p-type ATPase similar to the Menkes gene. (1993) Nat Genet 5(4): 327-337.

7. Nanji, M.S., Nguyen ,V.T., Kawasoe, J.H., et al. Haplotype and mutation analysis in Japanese patients with Wilson's disease. (1997) Am J Hum Genet 60(6): 1423-1429.

8. Yoo, H.W. Identification of noval mutations and the three most common mutations in the human ATP7B gene of Korean patients with Wilson's disease. (2002) Genet Med 4(6 Suppl): 43S-48S.

9. Tsai, C.H., Tsai, F.J., Wu, J.Y., et al. Mutation analysis of Wilson's disease in Taiwan and description of six new mutations. (1998) Hum Mutat 12(6): 370-376.

10. Wu, Z.Y., Wang, N., Lin, M.T., et al. Mutation analysis and the correlation between genotype and phenotype of Arg778 Leu mutation in Chinese patients with Wilson's disease. (2001) Arch Neurol 58(6): 971-976.

11. Tanzi, R.E., Petrukhin, K., Chernov, I., et al. The Wilson disease gene is a copper transporting ATPase with homology to the Menkes disease gene. (1993) Nat Genet 5(4): 344-350.

12. Vulpe C etal.(1993) Isolation of a candidate gene for Menkes disease and evidence that it encodes a copper transporting ATPase.Nat Genet 3: 7-13.

13. Bull, P.C., Thomas, G.R., Rommens, J.M., et al. The Wilson's disease gene $\mathrm{s}$ a putative copper transporting P-type ATPase similar to the Menkes gene. (1993) Nat Genet 5(4): 327-337.

14. Shah, A.B., Chernov, I., Zhang, H.T., et al. Identification and analysis if mutations in the Wilson's disease gene (ATP7B) population frequencies, genotype-phenotype correlation and functional analysis. (1997) Am J Hum Genet 61(2): 317-328.

15. Xu, Y.F., Fan, Y., Yu, L., et al. Identification of a mutation hotspot in exon 8 of Wilson's disease gene by cycle sequencing. (1998) Zhonghua Yi Xue Yi Chuan Xue Za Zhi 15(5): 284-287.

16. Valentine, J.S., Gralla, B. Delivering copper inside yeast and human cells. (1997) Science 278(5339): 817-818.

17. Thomas, G.R., Forbes, J.R., Roberts, E.A., et al. The Wilson's disease gene: spectrum of mutations and their consequences. (1995) Nat Genet 9(2): 210-217.

18. Kim, E.K., Yoo, O.J., Song, K.Y., et al. Identification of three novel mutations and a high frequency of the Arg 778Leu mutation in Korean patients with Wilson's disease. (1998) Hum Mutat 11(4): 275-278.

19. Gupta, A., Aikath, D., Neogi, R., et al. Molecular Pathogenesis of Wilson's disease: haplotype analysis, detection of prevalent mutations and genotype-phenotype correlation in Indian patients. (2005) Hum Genet 118(1): 49-57.

20. Schiefermeier, M., Kollegger, H., Madl, C., et al. The impact of apolipoprotein $\mathrm{E}$ genotypes on age at onset of symptoms and phenotypic expression in Wilson's disease. (2000) Brain 123(3): 585-590.

21. Harris, E.D. Cellular copper transport and metabolism. (2000) Annu Rev Nutr 20: 291-310.

22. Schilsky, M., Tavil, A.S. Wilson's disease. In Disease of the liver, edn 9, (Eds Schiff ER etal.) (2003) Philadelphia: Lippincott Williams and Wilkins p: 1169-1186.

23. Sherlock, S., Dooley, J. Wilson's disease.In diseases of the liver and Biliary system, (edn 11) (2002) Oxford: Blackwell Science p: 413-422. 24. Le Witt, P., Pfeiffe, R. Neurologic aspects of Wilson's disease: Clinical manifestations and treatment considerations. In Parkinson's disease and Movement Disorders, edn 4 (Eds Jankovic JJ and Tolosa E) (2002) Philadelphia: Lippincott Williams and Wilkins: 240-255.

25. Kalra, V., Khurana, D., Mittal, R. Wilson's disease: early onset and lessons from a pediatric cohort in India. (2000) Indian Pediatr 37(6): 595-601.

26. Starosta-Rubinstein, S., Young, A.B., Kluin, K., et al. Clinical assessment of 31 patients with Wilson's disease: correlations with structural changes on magnetic resonance imaging. (1987) Arch Neural 44(4): 365-370. 
27. Jha, S.K., Behari, M., Ahuja, G.K. Wilson's disease; clinical and radiological features. (1998) J Assoc physicians India 46(7): 602-605. 28. Brewer, G.J. Wilson's disease. In Neurogenetics scientific and clinical advances (Ed Lynch DR) (2006) New York: Taylor and Francis pp: 383-402.

29. Kawamura, N., Ohyagi, Y., Kawajiri, M., et al. Serial diffusion-weighted MRI in a case of Wilson's disease with acute onset hemichorea. (2004) J Neurol 251(11): 1413-1414.

30. Kuruvilla, A., Joseph, S. Face of the giant Panda sign in Wilson's disease: revisited. (2000) Neurol India 48(4): 395-396.

31. Meenakshi-Sundaram, S., Taly, A.B., Kamath, V., et al. Autonomic dysfunction in Wilson's disease-a clinical and electro physiological study. (2002) Clin Auton Res 12(3): 185-189.

32. Prashanth, L.K., Taly, A.B., Sinha, S., et al. Wilson's disease: diagnostic errors and clinical implications. (2004) J Neurol Neurosurg Psychiatry 75(6): 907-909.

33. Loudianos, G., Figus, A.L., Loi, A., et al. Improvement of prenatal diagnosis of Wilson's disease using microsatellite markers. (1994) Prenatal Dian 14(10): 999-1002.

34. Page, R.A., Davie, C.A., MacManus, D., et al. Clinical correlation of brain MRI and MRS abnormalities in patients with Wilson'disease. (2004) Neurology 63(4): 638-643.

35. Severn B. C., et al. Traumatic Brain Injury Causes a Tacrolimus-Sensitive Increase in Non-Convulsive Seizures in a Rat Model of Post-Traumatic Epilepsy (2014) Int J Neurol Brain Disord 1(1): 1-11.

36. Alanen, A., Komu, M., Penttinen, M., et al. Magnetic resonance imaging and proton MR spectroscopy in Wilson's disease. (1999) Br J Radiol 72(860): 749-756.

37. Savranlar, A., OZER, T., Aydemis, S., et al. Proton magnetic resonance spectroscopy findings of Wilson's disease: case report. (2005) J Neurol Sci (Turk) 22(3): 297-303.

38. Van Den Heuvel, AG., Van der Grond, J., Van Rooij, L.G., et al. Differentiation between portal-systemic encephalopathy and neurodegenerative disorders in patients with Wilson's disease H-1 MR spec- troscopy. (1997) Radiology 203(2): 539-543.

39. Lucato, L.T., Otaduy, M.C., Barbosa, E.R., et al. Proton MR spectroscopy in Wilson's disease: analysis of 36 cases. (2005) AJNR Am J Neuroradiol 26(5): 1066-1071.

40. Jeon, B., Kim, J.M., Jeong, J.M., et al. Dopamine transporter imaging with [1231]-beta-CIT demonstrate presynaptic nigrostriatal dopaminergic damage in Wilson's disease. (1998) J Neurol Neurosurg Psychiatry 65(1): 60-64.

41. Walshe, J.M. Pencillamine: the treatment of first choice for patients with Wilson's disease. (1999) Mov Disord 14(4): 545-550.

42. Walshe, J.M. Treatment of Wilson's disease with trientine( triethyl amine tetra amine dihydrochloride). (1982) Lancet 1(8273): 643-647.

43. Brewer, G.J., Hedera, P., Kluin, K.J., et al. (2003) Treatment of Wilson disease with ammonium tetrathiomolybdate: III. Initial therapy in a total of 55 neurologically affected patients and follow-up with zinc therapy. Arch Neurol 60(3): 378-385.

44. Hoogenraad, T.U., Van Hattum, J., Van den Hamer, C.J. (1987) Management of Wilson's disease with zinc sulphate: experience in a series of 27 patients. J Neurol Sci 77(2-3): 137-146.

45. Brewer, G.J., Dick, R.D., Yuzbasiyan-Gurkan, V., et al. Treatment of Wilson's disease with zinc. XIII: Therapy with zinc in presymptomatic patients from the time of diagnosis. (1994) J Lab Clin Med 123(6): 849-858.

46. Togashi, Y., Li, Y., Kang, J.H., et al. D-pencillamine prevents the development of hepatitis in Long-Evans Cinnamon rats with abnormal copper metabolism. (1992) Hepatology 15(1): 82-87.

47. Bax, R.T., Hässler, A., Luck, W., et al. Cerebral manifestation of Wilson's disease successfully treated with liver transplantation. (1998) Neurology 51(3): 863-865.

48. Nazer, H., Ede, R.J., Mowat, A.P., et al. Wilson's disease: clinical presentation and use of prognostic index. (1986) Gut 27(11): 13771381.

49. Ha-Hao, D., Merle, U., Hofmann, C., etal. Chances and short comings of adenovirus-mediated ATP7B gene transfer in Wilson's disease: proof of principle demonstrated in a pilot study with LEC rats. (2002) Z Gastroenterol 40(4): 209-216. 